\title{
DOS SONATAS NOVOHISPANAS PARA GUITARRA DEL SIGLO XVIII: UN CASO DE MUSICOLOGIA FORENSE*
}

\author{
Antonio Corona Alcalde
}

\begin{abstract}
Resumen:
En un artículo publicado en 1952 el musicólogo mexicano Miguel Bernal Jiménez dió cuenta de la existencia de una serie de catorce sonatas, descritas como "para dos guitarras", en el archivo musical de Santa Rosa de Valladolid (hoy Morelia, en el estado de Michoacán, México), actualmente perdidas. Por otra parte, en 1939, en un concierto de música novohispana organizado por el mismo Bernal Jiménez, se presentaron dos sonatas para guitarra procedentes de dicho archivo, ejecutadas por el solista Renán Cárdenas Pinelo, cuyas partituras, en copia moderna, han sobrevivido. Un estudio de estas partituras revela que probablemente se trate de obras escritas originalmente para guitarra y continuo, en el estilo de las que aparecen en el ejemplar veracruzano del método para guitarra de Antonio de Vargas y Guzmán, el cual data de 1776, modificadas con el objeto de tocarse a solo, y que pertenezcan a la serie mencionada por Bernal Jiménez cuyo paradero desconocemos en la actualidad.
\end{abstract}

\section{Palabras Clave:}

Sonata, guitarra, continuo, bajo, Morelia.

\begin{abstract}
:
In an article published in 1939 the Mexican musicologist Miguel Bernal Jiménez revealed the existence of a series of fourteen sonatas, described as "for two guitars", in the musical archive of Santa Rosa de Valladolid (now Morelia, in the state of Michoacán), nowadays lost. On the other hand, two sonatas for guitar from the same archive were played in a concert of music from New Spain, organized by the same Bernal Jiménez in 1939, by the guitarist Renán Cárdenas Pinelo, whose scores, in a modern copy, have survived. A study of these scores shows that the original was probably intended for guitar and continuo, in the same style as the sonatas that appear in the copy from Veracruz of the guitar treatise by Antonio Vargas y Guzmán, dating from 1776, modified in order that they could be played solo, and that the may belong to the series mentioned by Bernal Jiménez in 1952 whose whereabouts is at the present time unknown
\end{abstract}

Key Words:

sonata, guitar, continuo, "bajo", Morelia.

Un análisis de la situación de la guitarra en el mundo durante el siglo XVIII muestra un panorama un tanto peculiar: la escasa producción conocida de música para este instrumento produce la impresión de que decae el interés por él durante esta época, especialmente si se compara dicha penuria con la abundancia de obras para guitarra del siglo anterior. También resulta sorprendente constatar que inmediatamente después de este periodo, aparentemente tan pobre, surja con tal vigor la eclosión guitarrística del siglo XIX, capitaneada por figuras tales como Fernando Sor, Dionisio Aguado, Mateo Carcassi y Mauro Giuliani. Se puede especular sobre las causas de lo que, a primera vista, parecería un descenso de popularidad, especialmente en lo que se refiere al ámbito hispánico y su esfera de influencia, considerando factores sociales, socioculturales, modas y otros aspectos, sin llegar a resolver la

* El presente artículo está basado en una comunicación presentada en el IV Congreso Chileno de Musicología celebrado en Santiago de Chile en enero de 2007 con el título "Dos sonatas novohispanas para guitarra". 
cuestión. También es factible buscar las causas de esta carencia de fuentes en un fenómeno típicamente español, cuyas repercusiones merecen un estudio aparte: la escasa producción de los impresores españoles en lo que se refiere a libros de música ${ }^{1}$. Es conveniente recordar aquí que Gaspar Sanz tuvo que grabar el mismo las placas de su Instrucción de música sobre la guitarra española (1/Zaragoza, 1674), y que el impresor Melchor Álvarez improvisó como pudo la forma de imprimir las tablaturas de la obra de Lucas Ruiz de Ribayaz: Luz y Norte Musical (Madrid, 1677), sin llegar a obtener un resultado medianamente satisfactorio ${ }^{2}$. Hacia fines del siglo XVII, Francisco Guerau también tuvo que hacerse grabar las placas de su Poema Harmonico (Madrid, 1694), a pesar de lo cual se siguieron haciendo correcciones sobre la marcha ${ }^{3}$. Ya en el siglo XVIII Santiago de Murcia publica su Resumen de acompañar la parte con la guitarra (s.l., s.e., 1714); sin embargo, este libro no fue grabado en España, como lo atestigua la aprobación de Antonio Literes, quien declara que este libro fue "abierto en Amberes"4. Otros libros de Santiago de Murcia, tales como el "Pasacalles y obras de guitarra"

1 Hasta la fecha, los únicos estudios generales sobre impresión musical española se deben a Higinio Angles: "Der Musiknotendruck des 15-17 Jahrhunderts in Spanien”, en Scripta Musicologica, editado por José López-Calo, 3 vols. (Roma, 1979), III, pp. 1287-1296, y a Carlos José Gosálvez Lara, La edición musical española hasta 1936, Colección de Monografías AEDOM, No. 1 (Madrid: Asociación Española de Documentación Musical, 1995). Otros dos estudios, dedicados específicamente a la impresión de los libros de Tomás de Santa María y Luis de Narváez. son obra de John Griffiths y Warren E. Hultberg, "Santa Maria and the Printing of Instrumental Music in Sixteenth-Century Spain”, en Livro de homenagem a Macario Santiago Kastner, editado por Maria Fernanda Cidrais Rodrigues, Manuel Morais y Rui Veiera Nery (Lisboa, 1992), pp. 347-360; y Juan Ruiz Jiménez: "Luis de Narváez and Music Publishing in Sixteenth-Century Spain", Journal of the Lute Society of America, vols XXVIXXVII (1993-1994), pp. 1-15. El panorama general de la impresión de libros para vihuela es discutido por el mismo Griffiths en "Printing the Art of Orpheus: Vihuela Tablatures in Sixteenth-Century Spain", en Music, Print and Culture in Renaissance Iberia, editado por Ian Fenlon y Tess Knighton, Kassel: Edition Reichenberger, próximo a aparecer; quisiera agradecer al autor el proporcionarme una copia de su artículo antes de su publicación. Las condiciones desfavorables bajo las que laboraban las imprentas españolas son mencionadas por Juan José Rey en el prólogo a su edición del Ramillete de Flores (Madrid: Editorial Alpuerto, 1975), p. 10, y Gosálvez Lara, op. cit., p. 24 donde señala que "en la España renacentista no concurrieron las condiciones necesarias para que se diera en este campo un proceso similar al de otros países, y a pesar del progreso indudable de nuestro arte tipográfico, tardaría todavía casi trescientos años en cuajar aquí una actividad de impresión y edición de música verdaderamente significativa"; más adelante (p. 34) el mismo autor comenta que "dejando al margen las obras eclesiásticas, el número de piezas musicales grabadas o impresas en España durante el siglo XVIII que han llegado hasta nosotros es muy reducido, debido a que las circunstancias anteriormente expuestas habían impedido el nacimiento de una imprenta especializada suficientemente fuerte. Como en épocas precedentes, muchas composiciones de autores españoles o gestadas en España tuvieron que cruzar las fronteras para ser impresas en París, Viena, Leipzig, Ámsterdam o Londres (por ejemplo los Essercizi de Domenico Scarlatti y las sonatas de Antonio Soler editadas en 1772)". Véase también el estudio de Cristóbal Pérez Pastor "Escrituras de concierto para imprimir libros", Revista de Archivos, Bibliotecas y Museos, XXVI (1897), pp. 363-371, John M. Ward, "The Vihuela de mano and its Music (1536-1576)", tesis doctoral inédita, New York University, 1953, pp. 131-132; y Antonio Corona Alcalde, "The Fernández de Córdoba printers and the vihuela books from Valladolid”, Lute Society of America Quarterly, Vol. XXXX (mayo 2005), pp. 20-30.

2 El libro de Sanz, Instrucción de música sobre la guitarra española, se publicó por lo menos en ocho ediciones entre los años de 1674 y 1697; véase la nota bibliográfica de Luis García Abrines a la edición facsimilar publicada por la Institución Fernando el Católico (Zaragoza: CSIC, 1952), pp. XXXIII-XXXIV. Resulta significativo que Ruiz de Ribayaz reconozca el problema en su "Prologo al curioso lector", cuando trata de la cifra para el arpa: "Lo que asseguro es, que he procurado en lo que se llega à ejecutar, fuesse como se escriue comunmente, y con todos los requisitos que vsan, y han vsado los que enseñan por las cifras; esto no se ha podido ajustar en las Imprentas, auiendolo procurado en las mas de esta Corte, por el poco vso que ha tenido este genero de impression: antes impossibilitaban tanto la materia que fue preciso traducir la cifra del Arpa, pues para imprimir de la otra suerte, era necessario hazer caracteres nueuos con diferentes matrizes, lo qual no se ha podido ajustar, porque no ha auido quien lo haga; y aun para esta impression pusieron tantas dificultades algunos Impressores, que ha sido forçoso buscar arbitrio para hazerla, cuya nouedad puede disculpar los defectos de ella, de quien la ha manejado, y aun de su Autor, pues no es facil acertarla de la primera, la qual, y del genero no ay duda que es en España la de este libro", Lucas Luis de Ribayaz, Luz y norte musical para caminar por las cifras de la guitarra española... (Madrid: Melchor Álvarez, 1677), sig. ff.3. Este tratado fue publicado en facsímil, con un estudio y transcripciones de Rodrigo de Zayas y de María Rosa Calvo-Manzano por la Editorial Alpuerto, (Sevilla 1982).

3 Véase la introducción de Brian Jeffery a la edición facsimilar del Poema Harmonico (Londres: Tecla Editions, 1977), p. 7, donde se citan las diferencias de estado en las distintas copias que sobreviven. 
(1732), el denominado "Códice Saldívar IV" (s.d.), y una colección intitulada "Cifras selectas de guitarra" (1722) descubierta recientemente en Santiago de Chile existen solamente en manuscrito 5 . En este contexto de limitada producción editorial es razonable suponer que una buena parte de las obras que circulaban lo hacían por medio de copias escritas a mano que pudieron haberse perdido, lo cual ha sido confirmado por otros estudiosos de la imprenta musical y de la música española para guitarra ${ }^{6}$. Uno de los principales tratados guitarrísticos de ese siglo procedentes de la esfera cultural hispánica es la Explicación para tocar la guitarra de punteado por música o cifra [...] de Antonio de Vargas y Guzmán, el cual sobrevive precisamente en copias manuscritas, procedentes de ambos lados del océano, Cádiz y Veracruz ${ }^{7}$. Este importante tratado ayuda en buena medida a aliviar nuestra ignorancia

4 Santiago de Murcia, Resumen de acompañar la parte con la guitarra, s.l., s.e., 1714, edición en facsímil por Arte Tripharia (Madrid, 1984), pagina sin numerar frente a la p. 2. El Diccionario de Autoridades, vol, 1 (Madrid, 1726), edición en facsimil por Gredos (Madrid:, 1979), p. 22, define "ABRIR EN COBRE, U OTRO METAL" como "gravar en laminas de metal con el buril figuras y otras cosas, que se han de passar despues al papel por medio de la tinta y de la prensa [...]". Otros libros del siglo XVIII que recurren al grabado para la impresión del texto musical son: Diego Fernandez de Huete, Compendio numeroso de zifras armonicas, 2 vols (1/Madrid: Imprenta de musica, 1702; 2/Madrid: Imprenta de musica, 1704), publicado en facsimil con un estudio y transcripción de María Rosa Calvo Manzano por Alpuerto, (Madrid, 1992); y Pablo Minguet, Reglas y advertencias generales ... (Madrid: Joaquín Ibarra, 1754). Este ultimo tratado fue publicado en facsímil por Minkoff Reprint (Ginebra, 1981).

5 Tanto el manuscrito llamado "Pasacalles y obras de guitarra por todos los tonos naturales para el Sr D Joseph Albarez de Saa ${ }^{\text {drra }}$ por Santiago de Murzia año de 1732” como el Códice Saldívar IV fueron encontrados en México. El primero fue adquirido por Julian Marshall y llevado a la British Library, donde se encuentra con la signatura Add.Ms. 31640. Chanterelle Editions publicó un facsímil con introducción de Michael Macmeeken (Mónaco, 1979); este manuscrito es discutido en detalle por Monica Hall en su tesis doctoral "The Guitar Anthologies of Santiago de Murcia", 2 vols, Open University, 1983. El Códice Saldívar IV, adquirido en León, Guanajuato, en 1943 por el musicógrafo Gabriel Saldívar, ha sido publicado en facsímil por Michael Lorimer (Santa Barbara: s.e., 1987). Esta misma fuente ha sido estudiada y transcrita por Craig Russell, Santiago de Murcia's "Códice Saldivar No. 4": a Treasury of Secular Guitar Music from Baroque Mexico, 2 vols. (Chicago, Illinois: University of Illinois Press, 1995). El manuscrito "Cifras selectas de guitarra" fue descubierto por Alejandro Vera, quien lo describe en "Una nueva fuente para la música del siglo XVIII: el manuscrito Cifras Selectas de Guitarra de Santiago de Murcia (1722)”, Resonancias, No. 18 (Mayo de 2006), pp. 35-49.

6 Es interesante el comentario de Carlos José Gosálvez Lara, op. cit., p. 44, acerca de la circulación de copias manuscritas: "La falta de una imprenta musical sólida, sin duda motivada por una carencia de demanda real, hizo posible la proliferación de 'ediciones' manuscritas, especialmente de música española, debido que las expectativas de venta no compensaban el gasto de grabado. Estas partituras manuscritas solían ser realizadas por copistas profesionales por encargo de los libreros". Luis Briso de Montano confirma este hecho en su artículo "Un fondo desconocido de música para guitarra: ¿Los papeles de D. Antonio Chocano?", publicado en la página de Internet. http://www.guitarandluteissues.com/ufd1.htm\#v1 (acceso 14/VI/2007), en el cual reseña varios manuscritos contenidos en una colección resguardada en la Biblioteca Municipal de Madrid. El autor se pregunta el por qué no se ha conservado la música que se ponía a la venta por medio de numerosos anuncios en los periódicos de la época, y se responde diciendo "La respuesta es relativamente sencilla: la distribución de esa música se hacía a través del manuscrito, no del impreso [...], y los manuscritos tienen un grado mucho menor de perdurabilidad que los impresos", a lo cual añade posteriormente, al comentar las obras de la Biblioteca Municipal, que "la mayoría de los manuscritos contienen música española" en oposición a los impresos que provienen en su totalidad de París.

7 Se conocen tres copias del tratado de Vargas y Guzmán: la más antigua, fechada en Cadiz en 1773, lleva el título de "Explicación De la Guitarra de Rasgueado, Punteado, y haciendo la Parte de el Baxo repartida en tres Tratados" se encuentra en la biblioteca particular de Ángel Medina Álvarez, quien lo publicó como Juan Antonio de Vargas y Guzmán. Explicación de la Guitarra (Cadiz, 1773) (Granada: Centro de Documentación Musical de Andalucía, 1994), mencionada en adelante como Vargas 1773. Otra copia, con variantes importantes, se encuentra en el Archivo General de la Nación de México, Galería 4, Virreinato, Secretaría de Cámara, caja 349, está fechada en Veracruz en 1776 y su título es: "Eplicacion [sic] Para tocar la Guitarra de Punteado por Mussica o Cifra, y reglas Vtiles para Acompañar con ella la Parte de el Baxo"; se publicó en facsímil, con un estudio analítico y con una transcripción de las sonatas que contiene, por Juan José Escorza y José Antonio Robles Cahero (Mexico: Archivo General de la Nación, 1986), mencionado en lo sucesivo como Vargas 1776. La última copia, localizada en la Newberry Library de Chicago con la signatura Case VMY 582 V29e", lleva por título "EXPLICACION PARA TOCAR LA GUITARRA DE PUNTEADO POR MUSICA O SIFRA Y REGLAS UTILES PARA ACOMPAÑAR LA PARTE DEL BAJO”, fechada asimismo en Veracruz en 1776, es una copia del ejemplar del Archivo General de la Nación. De acuerdo con Medina (op. cit., p. xiv), las copias de su biblioteca y la del Archivo General de la Nación proceden de la misma mano, concluyendo que "presumiblemente el propio Vargas y Guzmán es el copista del tratado de Cádiz y de uno de los de Veracruz, el conservado en México". 
sobre la música secular del siglo XVIII, y nos ratifica que el panorama no es, de ninguna manera, tan desolador como lo pudieran sugerir las escasas fuentes impresas que se conocen.

El ejemplar veracruzano del tratado de Vargas y Guzmán custodiado en el Archivo General de la Nación incluye trece sonatas para guitarra y continuo, a las que vienen a sumarse ahora otras dos sonatas, probablemente contemporáneas, de autor anónimo y factura muy similar, procedentes del Archivo Musical de Santa Rosa de Valladolid (hoy Morelia), y que posiblemente formaban parte de una serie de catorce, descritas como "sonatas a dos guitarras" en un artículo publicado en 1952 por el compositor y musicólogo Miguel Bernal Jiménez donde se describe el contenido del archivo mencionado (Ilustración 1) ${ }^{8}$.

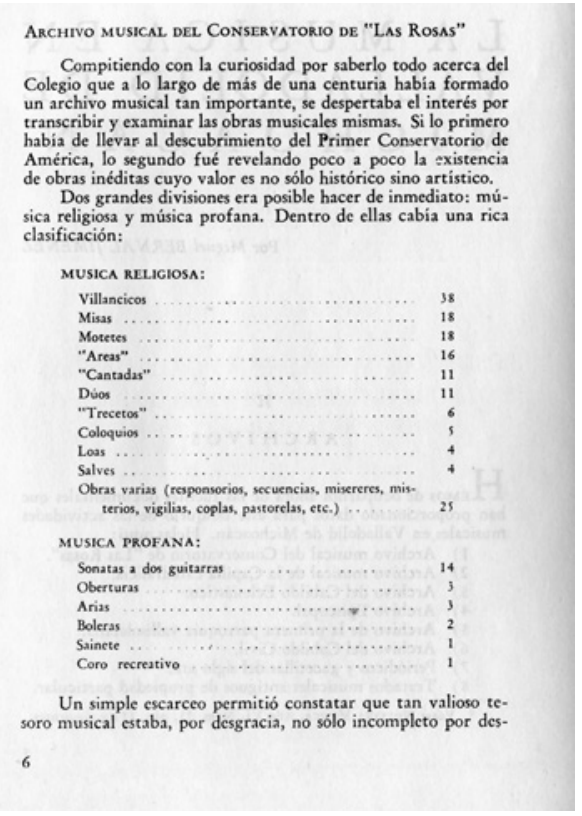

\section{Ilustración 1. Miguel Bernal Jiménez: "La música en Valladolid de Michoacán. Parte 2. Archivos”, Nuestra Música, VIII/25 (primer trimestre, 1952), p.6}

Desgraciadamente el paradero actual de los originales es desconocido, y estas dos sonatas llegan hasta nosotros en copias modernas preparadas para que se tocaran en un concierto intitulado "Morelia Colonial", conformado exclusivamente por obras novohispanas provenientes del archivo citado, el cual tuvo lugar el 30 de mayo de 1939 en el Teatro Ocampo de la misma ciudad. El programa de este concierto (Ilustración 2) aparece en el trabajo de Bernal Jiménez intitulado Morelia Colonial. El archivo musical del colegio de Santa Rosa de Santa Maria de Valladolid, publicado el mismo año de 1939, donde se incluye asimismo un breve comentario sobre estas piezas (Ilustración 3) ${ }^{9}$.

8 Miguel Bernal Jiménez, "La música en Valladolid de Michoacán. Parte 2. Archivos”, Nuestra Música, Vol. VIII, No. 25 (Primer trimestre, 1952), pp. 5-16 (p. 6).

9 Miguel Bernal Jiménez, Morelia Colonial. El archivo musical del colegio de Santa Rosa de Santa Maria de Valladolid (Siglo XVIII) (México: Ediciones de la Universidad Michoacana de San Nicolás, 1939), pp 17 y 19. 


\section{Miguel Bernal Jiménez: Morelia Colonial. El archivo musical del colegio de Santa Rosa de Santa María de Valladolid (Siglo XVIII).}

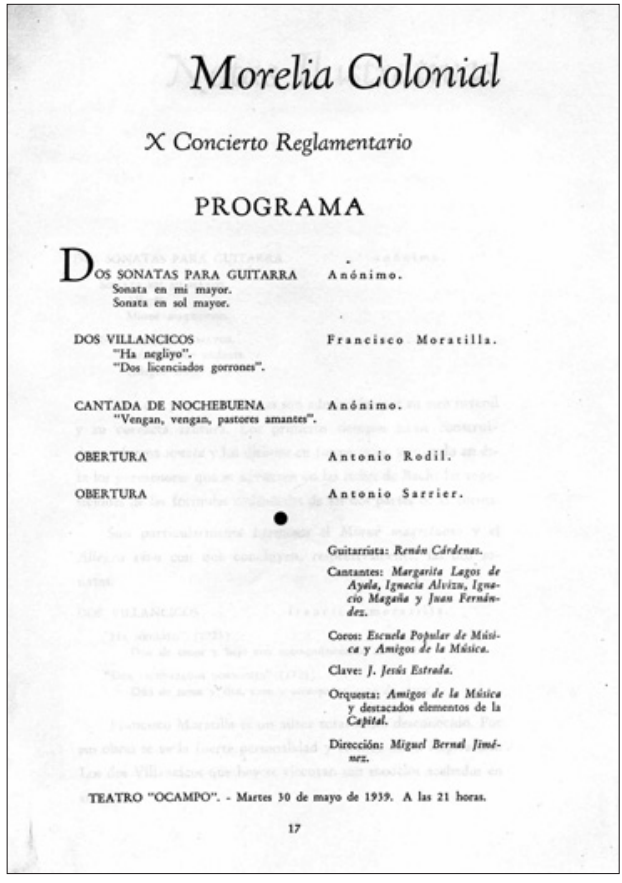

Ilustración 2. Pág.17.

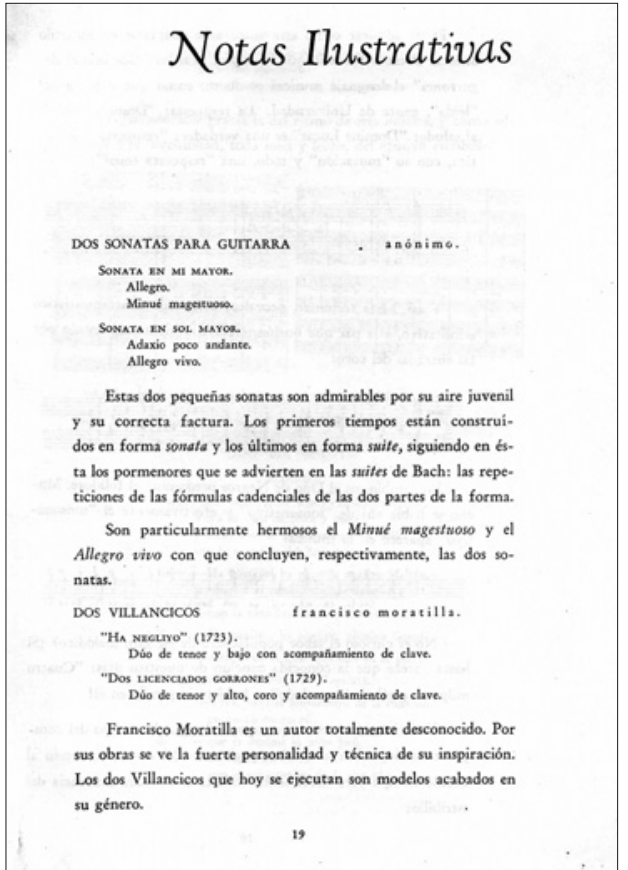

Ilustración 3. Pág.19: "notas ilustrativas"

Es notable que, a pesar de haber formado parte del repertorio de dicho concierto, las sonatas que nos ocupan no se encuentran en el catálogo de las obras del archivo de Santa Rosa que aparece en la publicación de 1939, especialmente cuando las copias modernas indican claramente su procedencia (Ilustración 4), una omisión que seguramente fue corregida en el artículo de 1952. Es muy razonable suponer que fue el mismo Bernal Jiménez, responsable de la organización y dirección del concierto -y que trabajó exhaustivamente en el archivo moreliano- quien proporcionó las copias al guitarrista Renán Cárdenas Pinelo, encargado de tocar las sonatas en dicha ocasión, en la cual se ejecutaron también obras de otros autores novohispanos tales como Francisco Moratillo, Antonio Rodil y Antonio Sarrier.

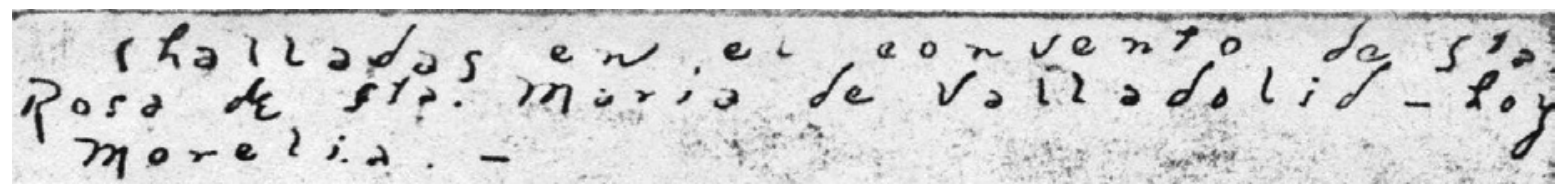

Ilustración 4. Rúbrica confirmando que las sonatas proceden del archivo del Convento de Santa Rosa de Santa María de Valladolid. 
La copia de las sonatas que sirve de base al presente trabajo procede del archivo de la viuda de Renán Cárdenas, quien cedió una fotocopia al guitarrista y erudito musical Juan Helguera, a quien debo la gentileza de proporcionarme una reproducción (Ilustraciones 5-8).

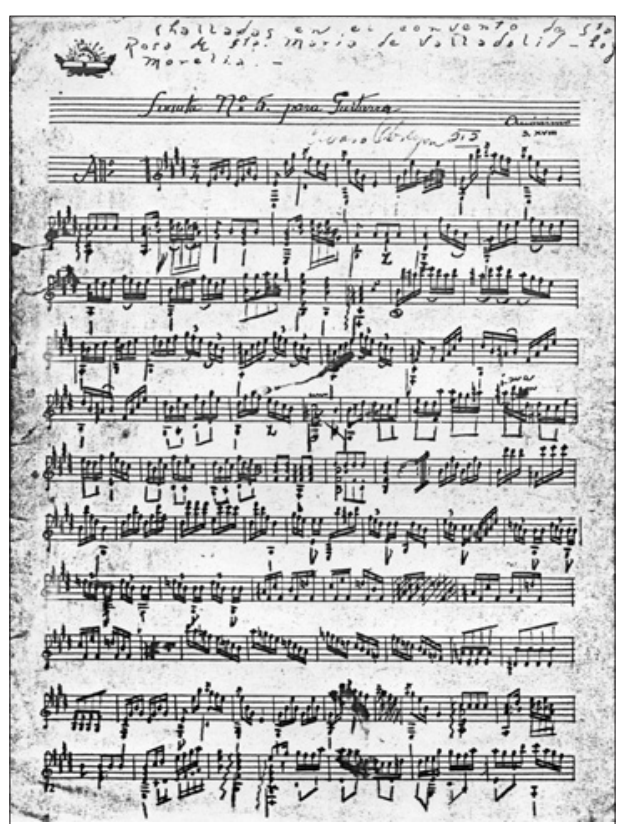

Ilustración 5. Allegro vivo.

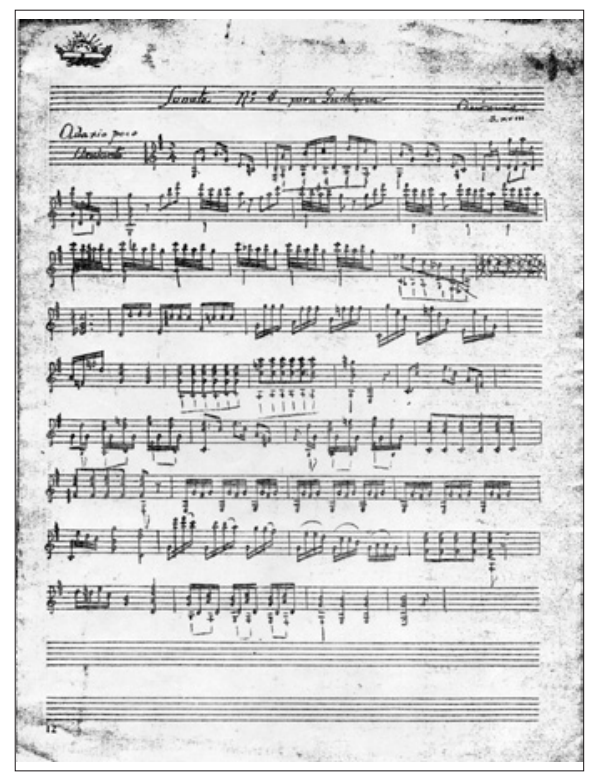

Ilustración 7. Adagio poco andante.
Sonata 5

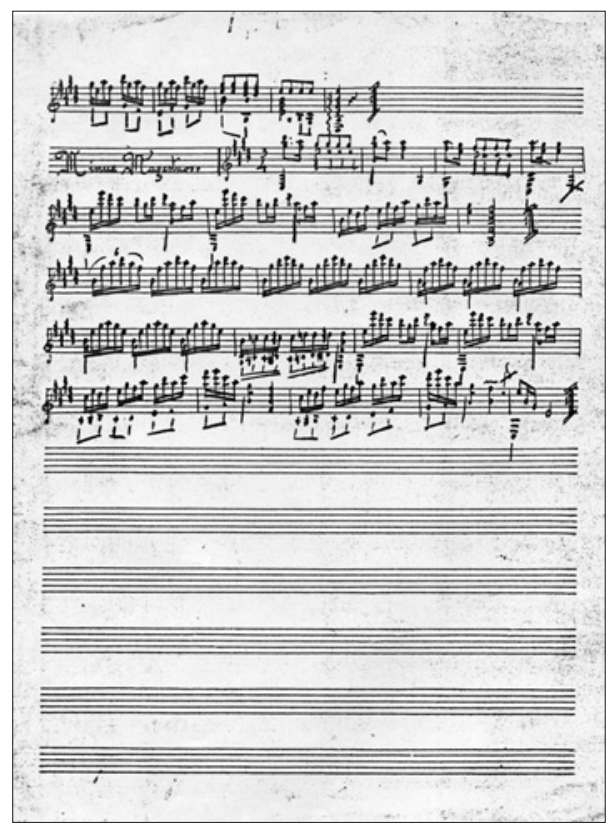

Ilustración 6. (Conclusión) "Minué Majestuoso"

Sonata 8

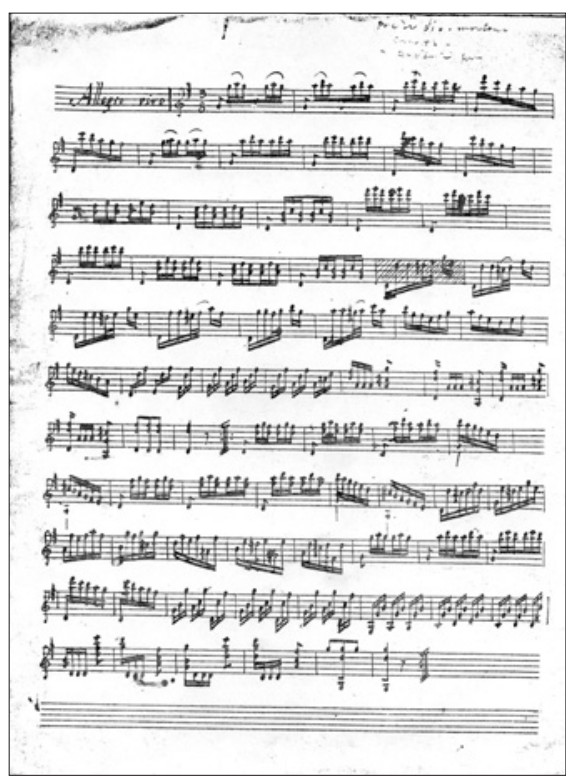

Ilustración 8. Allegro vivo 
Desafortunadamente es muy poco lo que esta copia, escrita en papel ostensiblemente moderno como lo demuestra la marca "Ideal" en la esquina superior de dos de las hojas (Ilustración 9), puede decirnos acerca del origen de estas piezas.

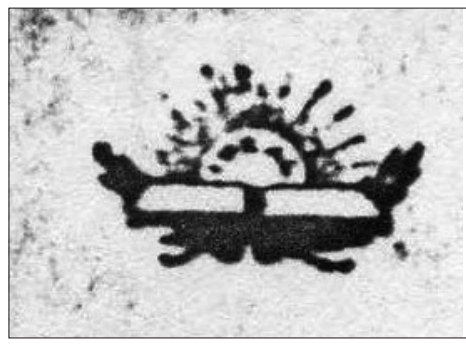

\section{Ilustración 9. Marca “Ideal” en el papel.}

En la escritura se distinguen claramente dos manos: la primera es autora de las rúbricas "Sonata No, 5 para Guitarra" y "Sonata No. 8 para Guitarra", así como de la parte correspondiente a la melodía en escritura "tipo violín" típica de las primeras fuentes para guitarra en notación moderna ${ }^{10}$. La segunda mano añadió una serie de bajos y rellenó algunos acordes (Ilustraciones 10 y 11).

\section{Dos manos en la escritura: Sonata 8, Adagio poco andante}

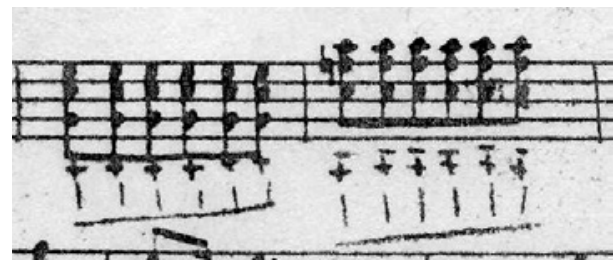

Ilustración 10. Compases 17-18.

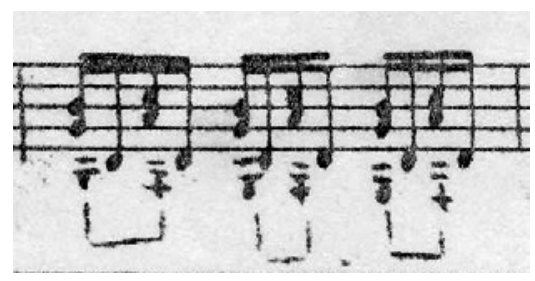

Ilustración 11. Compás 34

Esto hace pensar que el primer escribano pudo haber realizado la copia directamente del manuscrito -seguramente concebido para guitarra y continuo a semejanza de las sonatas de Vargas y Guzmán, como sugiere la posterior referencia de Bernal Jiménez a la serie de catorce "sonatas para dos guitarras", y como intentaré demostrar- y que la segunda mano pudiera ser la de Cárdenas Pinelo, quien incorporó las adiciones con el objeto de preparar una versión más adecuada para guitarra sola, el formato con que estas piezas fueron tocadas en el concierto ${ }^{11}$.

10 Véase Harvey Turnbull, The Guitar from the Renaissance to the Present Day (Londres: Batsford, 1/1974; 3/1978), p. 60; y Luis Briso de Montano, op. cit.

11 El primer copista pudo haber sido Bonifacio Rojas, alumno de Bernal Jiménez. Información proporcionada por Lorena Díaz Núñez, especialista en Bernal Jiménez y su música. 
Las obras presentadas aquí llevan como titulo "sonatas", pero es necesario aclarar que el término no se refiere a la sonata de estructura ternaria desarrollada a fines del siglo XVIII por la escuela vienesa, sino a la sonata bipartita que aparece consistentemente en España desde la primera mitad del siglo. Al pensar en la sonata ibérica del siglo XVIII acuden a la mente nombres famosos, que muy bien pueden considerarse como ilustres predecesores de las piezas que nos ocupan, tales como Domenico Scarlatti, Sebastián de Albero, Carlos Seixas o el padre Antonio Soler. El término "sonata", como es bien sabido, se aplicaba a obras para uno o, cuando mucho, para dos instrumentos, generalmente compuestas de varios movimientos, si bien la sonata de un solo movimiento no es de ninguna manera desconocida; basta con recordar las que escribió Scarlatti, intitulándolas originalmente Escercizi. Es muy posible que ciertas sonatas para guitarra anunciadas en la Gazeta de Barcelona en 1780, 1788 y 1789 correspondan también a la forma bipartita típica de la sonata hispánica ${ }^{12}$. En el caso de las obras del archivo de Santa Rosa, el primer movimiento de la Sonata 5, un Allegro, respeta la forma bipartita, al igual que el "Minue Magestuoso" que lo complementa como segundo movimiento, el cual también está constituido por dos secciones. En cambio, el primer movimiento de la Sonata 8, un "Adagio poco Andante" no responde a este patrón que, sin embargo, sí se encuentra en el segundo movimiento: "Allegro vivo". Como se ha mencionado, la sonata era fundamentalmente una obra para uno o dos instrumentos de cuerda o aliento, en oposición a la cantata para voces o la tocata para tecla, y desde esta perspectiva se puede aplicar con corrección el término a las obras bajo estudio; también es conveniente recordar que el mismo Vargas y Guzmán nombró "sonatas" a algunas de las obras que aparecen en su tratado, y que tampoco corresponden a la forma bipartita. Se ha sostenido la tesis, acertada a mi juicio, de que Vargas dispuso la colocación de sus piezas de acuerdo con un plan cuidadoso, agrupándolas por "tonalidades" con la intención de que pudieran tocarse en grupos de tres ${ }^{13}$; cada uno de estos grupos contiene, por lo menos, una sonata de forma $\mathrm{AB}$, colocada como primer movimiento, cuyo tempo es en tres casos Allegro y en el cuarto Moderato. Las sonatas morelianas presentan una cierta similitud con el esquema de Vargas y Guzmán: en la denominada "Sonata 5" los dos movimientos, Allegro y "Minue Magestuoso", se encuentran en la "tonalidad" de Mi mayor, mientras que los movimientos respectivos de la "Sonata 8", Adagio poco andante y Allegro vivo, tienen como "tonalidad" a Sol mayor ${ }^{14}$. Ante estos antecedentes cabe preguntarse si el Adagio poco Andante que inicia la Sonata 8 de Morelia, y que no responde a la forma $\mathrm{AB}$, ¿no será de hecho el segundo movimiento de un grupo cuyo primer movimiento se omitió en el recital de "Morelia Colonial"? La referencia a las catorce sonatas para dos guitarras en el artículo publicado por Bernal Jiménez en 1952, trece años después del concierto, sugiere -como se ha mencionado- la posibilidad de que las dos sonatas ejecutadas por Cárdenas

12 En la Gazeta del sábado 9 de septiembre de 1780 se anunciabn: "una sonata y el fandango para la guitarra de seis órdenes punteado: por Don Juan Garcia"; el sábado 13 de septiembre de 1788 se ponía a la venta: "una sonata para guitarra, su autor Pedro Soliveres"; el sábado 31 de enero del año siguiente apareció la siguiente nota: "Una sonata en música y cifra para guitarra"; finalmente el martes 11 de agosto del mismo año de 1789 se anunciaba la venta de: "una sonata y seis minues del Sr. Laporta: otra del Sr. Brito, Portugues: el fandango, la guaracha y seis contradanzas, todo en cifra para guitarra". Véase Briso de Montano, op. cit.; y Josep María Mangado, suplemento al libro La Guitarra en Cataluña 1769-1939 (Londres: Tecla, 1998), "Anuncios de obras para guitarra en 1780 a 1789 en la 'Gazeta de Barcelona'”, publicado en la pagina web:

http://www.tecla.com/extras/0001/0375/0375supp.htm (acceso14/VI/2007). La misma información también aparece en la página del Centro de Investigación y Documentación de la Guitarra Clásica en Cataluña, http://www.arrakis.es/ dedeo/05-prensa.gb.htm. 13 Juan José Escorza y Antonio Robles Cahero en Vargas 1776, I, p. 62. 
en dicha ocasión hubieran sido seleccionadas de entre ese grupo. Resulta significativo en este contexto que en el inventario del archivo, consignado en el artículo referido, no aparezca ninguna otra obra para guitarra que pudiera identificarse con las piezas objeto de nuestro estudio. A partir de estos datos podemos proponer como hipótesis el que Cárdenas realizara en 1939 una adaptación para guitarra sola de las cuatro piezas que ejecutó, mismas que de hecho serían obras para dos guitarras -o posiblemente guitarra y continuo- de la serie mencionada posteriormente por Bernal Jiménez, en 1952. Desafortunadamente el musicólogo moreliano no proporciona ninguna información que nos permita determinar si la fuente original consideraba como "sonatas" a las obras separadas, tal y como lo hace Vargas y Guzmán, o si las entradas en su inventario se refieren a catorce series de varias piezas. El uso del dieciocho parecería inclinar la balanza por la primera posibilidad, pero la segunda no puede descartarse por completo precisamente por la presentación que se hace de los pares de piezas como "sonatas" en el programa del concierto, así como por la evidencia que proporciona una sonata para guitarra sola de Antonio Abreu, en tres movimientos, que data de c. $1790^{15}$.

El primer movimiento de la Sonata 5 y el segundo de la 8 presentan ciertos problemas que pueden atribuirse a errores de copia. En el caso del Allegro de la Sonata 5 encontramos el compás 23 copiado dos veces (Ilustración 12), mientras que la secuencia armónica entre los compases 17 y 18 se interrumpe de manera brusca y con una pésima conducción de voces.

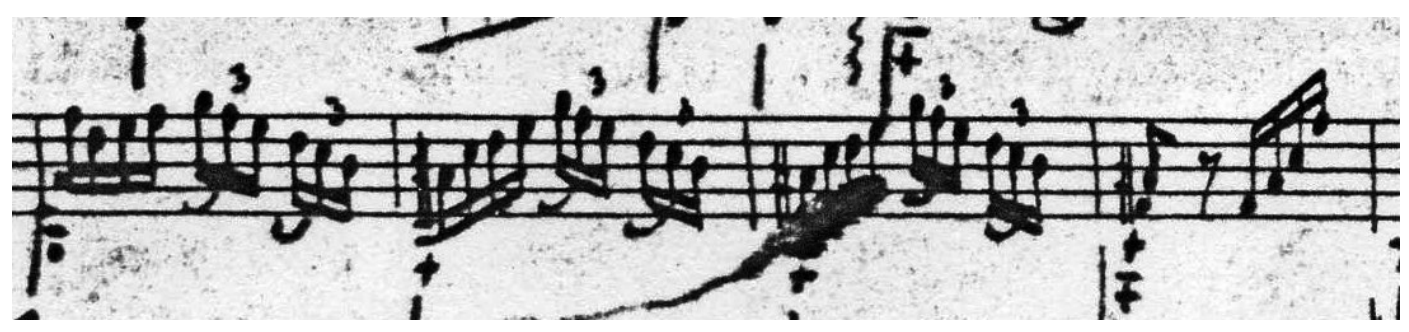

Ilustración 12. Compás copiado dos veces: Sonata 5, compases 23 (duplicado) - 25.

14 Es importante señalar que el concepto de tonalidad todavía no adquiría una vigencia completa entre la mayoría de los teóricos y músicos españoles del siglo XVIII, quienes continuaban manejando, con ciertas modificaciones, el sistema modal heredado del renacimiento. Incluso todavía encontramos en métodos y tratados del final del siglo la nomenclatura antigua de las notas como Csolfaut, Dlasolre, etc. Véase, por ejemplo, el tratado de Manoel da Paixaõ Ribeiro, Nova arte de viola, que ensina a tocalla com fundamento sem mestre [...] (Coimbra: na Real Officina da Universidade, 1799), p. 17, o el Arte de tocar la guitarra española por música (Madrid: Imprenta de Pantaleon Aznar, 1799) de Fernando Ferrandiere, p. 1, donde se describe la afinación de la guitarra con dicha nomenclatura, aunque también hay que reconocer que este último autor ya menciona (p. 8) el uso de dos modos cuando, al mencionar varios elementos de la música, incluye: "dos tonos, mayor y menor". En el presente caso se ha hablado de tonalidades de Sol mayor y de Mi mayor por consideraciones puramente pragmáticas, pero también es necesario aclarar que se trata de un manejo potencialmente anacrónico e inadecuado de la terminología. Más adelante se discutirán algunas de las posibles implicaciones del sistema modal en relación con las sonatas objeto de nuestro estudio. Existe una edición facsimilar de la obra de Ferrandiere, publicada por Tecla Editions (Londres, 1977), el tratado de Paixaõ Ribeiro se publicó, también en facsímil, por Minkoff (Ginebra, 1985).

15 Entre las obras de la colección custodiada en la Biblioteca Municipal de Madrid se encuentra, con la signatura 720-20(1), una "Sonata a solo" para guitarra de 5 ordenes de Antonio Abreu, que data de c.1790. De acuerdo con Luis Briso de Montano, op. cit., esta obra consta de tres movimientos. "All. . cómodo" (Do Mayor), "Largo" (do menor) y "Alleg. " (Do Mayor)". Abreu fue autor, junto con Víctor Prieto, de un método intitulado Escuela para tocar con perfección la guitarra de cinco y seis ordenes (Salamanca 1/1779, 2/1799). 
Por otra parte, en el Allegro vivo de la Sonata 8 aparece una progresión evidentemente dirigida hacia el quinto grado que se resuelve de manera muy poco satisfactoria en la tónica (Ilustración 13);

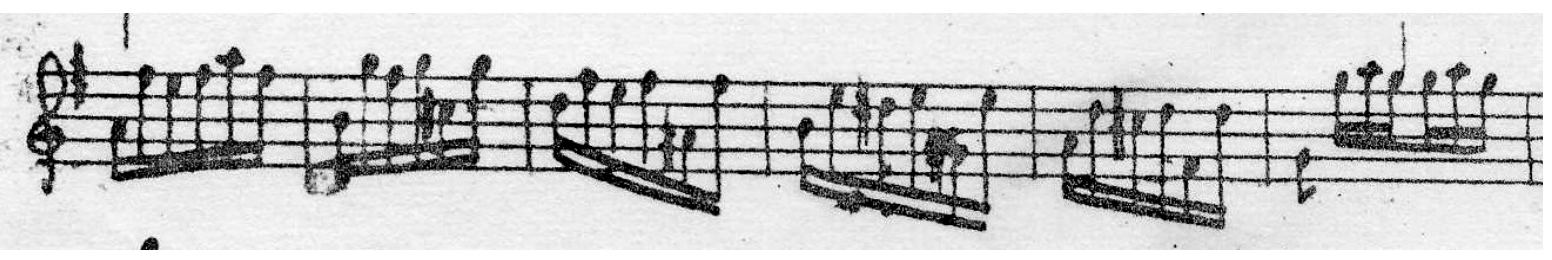

Ilustración 13. Progresión defectuosa: Sonata 8, Allegro vivo, compases 39-45.

el manejo descuidado de la armonía sugiere que el copista pudo omitir algunos compases. Si éste fuera el caso, surge otra pregunta: ¿cuál de los posibles copistas pudo equivocarse? La falta del original no permite responder con certeza y, en consecuencia, podemos postular dos opciones: los errores se deben al autor de la copia moderna, que denominaremos $\boldsymbol{Z}$; o bien aparecen en el ejemplar del cual $\boldsymbol{Z}$ fue copiado, al cual llamaremos $\boldsymbol{Y}$. Esta segunda alternativa plantea, por su parte, nuevas preguntas: si existen errores en $\boldsymbol{Y}$, ¿de donde proceden? La variedad de posibles respuestas se puede reducir fundamentalmente a dos esquemas: $\boldsymbol{Y}$ es el original; o bien existió un numero indeterminado de pasos intermedios en la transmisión, comenzando por el original, que llamaremos $\boldsymbol{A}$, hasta llegar a $\boldsymbol{Y}$. Estos esquemas se pueden representar gráficamente de la siguiente manera:

$$
\begin{gathered}
(A=Y) \rightarrow Z \\
A \rightarrow[N \rightarrow] Y \rightarrow Z
\end{gathered}
$$

Es muy probable que $\boldsymbol{A}$ fuese un manuscrito, posiblemente el original del autor; mientras que el manejo deficiente de la armonía en el pasaje del Allegro de la Sonata 8 en $\boldsymbol{Z}$ contrasta con el resto de la obra, la cual es impecable desde este punto de vista. Parecería poco factible que el autor de las copias modernas, realizadas con el objeto de presentar estas obras en un concierto de importancia, pudiera haber cometido una omisión tan seria, a lo cual habría que añadir que el posible descuido al copiar dos veces el mismo compás y también posiblemente omitir uno o varios acordes o copiar uno equivocado en el Allegro de la Sonata 5 resultaría igualmente vergonzoso en dichas circunstancias: serían demasiados errores. Estas consideraciones sugieren que existió por lo menos un paso intermedio $(\boldsymbol{A} \rightarrow \boldsymbol{Y} \rightarrow$ $\boldsymbol{Z})$, y que pudo cometerse el error al copiar $\boldsymbol{Y}$ de $\boldsymbol{A}$. Naturalmente, es factible que la cadena constara de otros eslabones, lo cual aumentaría las posibilidades de un copista despistado. Si esta última suposición es correcta, nos encontraríamos ante obras que gozaron de una cierta difusión; añadiendo a esto la reducida dificultad técnica que presentan, es posible suponer que estas obras hubiesen tenido una cierta circulación entre los guitarristas morelianos del siglo XVIII. Es necesario presentar aquí una excusa por lo poco riguroso del procedimiento para establecer esta hipótesis, pero se puede alegar como atenuante que la falta de documentación original nos fuerza a especular.

Según sus rúbricas, las sonatas objeto de nuestro estudio fueron escritas "para guitarra", pero es necesario precisar más el sentido del término, ya que durante la segunda mitad del siglo XVIII 
-fecha probable de su composición a juzgar por el estilo similar a las que aparecen en el tratado de Vargas y Guzmán- coexistieron diferentes tipos de guitarra. Durante el siglo XVII la guitarra se encordaba generalmente con cinco órdenes o pares de cuerdas, practica que persistió hasta la época que nos interesa aquí. Las múltiples reimpresiones del método de Joan Carles Amat para "guitarra española", es decir, para el instrumento que ahora conocemos como "guitarra barroca" de cinco órdenes, aparecen durante un periodo que abarca desde 1596 hasta cerca de $1800^{16}$. A esta prueba fehaciente de la continuidad del instrumento deben añadirse los diversos plagios que se hicieron de la obra de Amat, tales como el Liçam instrumental da viola portuguesa, ou de ninfas, de cinco ordens, publicado por una cierta Doña Policarpia "maestra de viola" en Lisboa en 1752, o el perpetrado por Andrés de Sotos con el titulo de Arte para aprender con facilidad y sin maestro, a templar y tañer rasgado la guitarra, de cinco ordenes o cuerdas, y también la de cuatro o seis órdenes, llamada guitarra española [...], publicada en Madrid por la imprenta de López en $1760^{17}$. A pesar de que la supervivencia de la guitarra de cinco órdenes está ampliamente probada por éstos y otros documentos, el instrumento usado con mayor frecuencia disponía de más cuerdas, a juzgar por la profusión de métodos dedicados a la "guitarra de seis órdenes" que aparecen en la última década del siglo XVIII ${ }^{18}$. Entre estos se pueden incluir tres obras didácticas publicadas el año de 1799: los Principios para tocar la guitarra de seis ordenes de Federico Moretti, la obra de Fernando Ferrandiere Arte de tocar la guitarra española por música, y la Escuela para tocar con perfección la guitarra de cinco y seis ordenes de Antonio Abreu y Víctor Prieto ${ }^{19}$. Vargas y Guzmán confirma en 1773 la preferencia de que gozó la guitarra de seis órdenes, considerándola como la más común:

"El instrumento de la Guitarra se compone, y consta de seis órdenes de Cuerdas duplicadas respectivamente. Digo seis porque son las mas comunes en el día e introducidas, y aun las mas perfectas, por cuanto contienen los veintiún signos"20.

16 Joan Carles Amat, Guitarra española, y vandola en dos maneras de Guitarra, Castellana, y Cathalana de cinco Ordenes ..., 1/1596 [perdida]; 2/Lérida, 1612; 3/Lérida, 1627; 4/Gerona, 1639; 5/Gerona: Gabriel Bro, 1745; 6/Gerona: Antonio Oliva, c.1750; 7/Valencia: Agustin Laborda, 1758; 8/Gerona: Joseph Bro, c.1761; 9/Valencia: La Viuda de Agustin Laborda, c. 1780; 10/Valencia: F. Burguete, c. 1800). La edición de Gerona, c.1761 fue publicada en facsímil por Chanterelle (Mónaco, 1980).

17 Véase Frederic F. Grunfeld, The Art and Times of the Guitar (Nueva York-Londres: Macmillan, 1969), p. 71. El método de Sotos fue publicado en facsímil por el Servicio de Reproducción de Libros de la librería París-Valencia (Valencia, s.d.); Grunfeld, op. cit, loc. cit, menciona otra edición de Madrid: Imprenta de la Cruzada, 1764, e incluye una reproducción de la portada.

18 La Gazeta de Barcelona anuncia el martes 17 de octubre de 1780 la venta de "várias piezas de música para guitarra de 5. y de 6. órdenes compuestas por D. Antonio de Abreu, Portugués"; dos años más tarde, el martes 26 de noviembre, se anuncian "Quatro piezas nuevas en música con baxo de tres partes cada una: á saber una pastorela, un minuet y una contradanza para guitarra de cinco órdenes, y una contradanza igualmente para seta [sic] orden; y asimismo puede servir para clave". Véase Mangado, op. cit. Por otra parte, las primeras noticias sobre la guitarra de seis ordenes datan de Madrid en.1760 y 1772 (Briso de Montano, op. cit); las primeras obras conocidas para este instrumento aparecen en los tratados de Vargas y Guzmán y posteriormente, en febrero y septiembre de 1780, se anuncian en la misma Gazeta de Barcelona varias obras para guitarra de seis ordenes (véase la nota 12).

19 Véanse las notas 13 y 14. Los Principios para tocar la guitarra de seis ordenes de Federico Moretti fueron publicados en Madrid por Josef Rico el mismo año de 1799.

20 Vargas 1773, p. 9; Vargas 1776, II, p. 3 repite literalmente el mismo concepto. 
Vargas reconoce que también existían guitarras de cinco y siete órdenes, pero el testimonio mencionado nos corrobora que su uso era más restringido. Si bien la versión de las sonatas de Morelia escrita por la primera mano presenta una gran parquedad en el uso de bajos, ocasionalmente aparecen algunos que nos definen con precisión para qué tipo de instrumento fueron escritas: en el minué de la sonata 5, compases 1 y 4 (Ilustración 14), así como en el primer movimiento de la sonata 8, compás 19, aparece el Mi correspondiente al sexto orden (Ilustración 15);

\section{Bajos en el sexto orden}

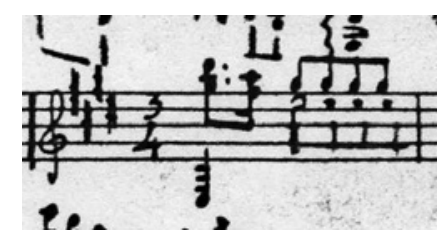

Ilustración 14. Sonata 5, Minué, compás 1.

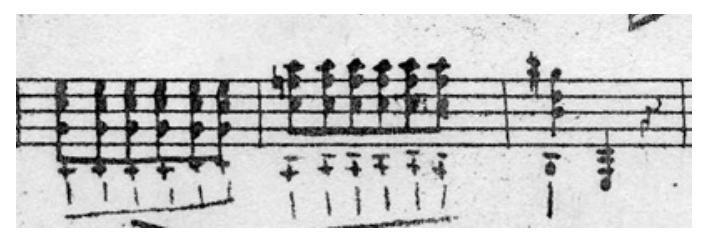

Ilustración 15. Sonata 8, Adagio poco andante, compás 19.

en consecuencia, el candidato más idóneo para la ejecución original de estas obras parece ser, en efecto, una guitarra de seis pares de cuerdas. Según las explicaciones de Vargas y Guzmán, la afinación de este instrumento es similar a la de la guitarra moderna, con la salvedad de que, en los órdenes del cuarto al sexto una de las cuerdas de que constaba cada par se afinaba una octava arriba, mientras que del tercero al primero ambas se afinaban al unísono. Esta afinación, añade Vargas, "es general para tocar la Guitarra de Rasgueado y Punteado", pero sugiere afinar los bordones al unísono para tocar bajo continuo $^{21}$. Las guitarras con cuerdas sencillas ya eran conocidas fuera de España, pero las guitarras españolas de la época -y por lo tanto se puede inferir que también las novohispanas- seguían encordándose con órdenes dobles. Para confirmar esto, además del texto de Vargas y Guzmán, contamos con el testimonio de Federico Moretti, quien declara en sus Principios para tocar la guitarra de seis ordenes de 1792 que los franceses e italianos podían afinar más rápido, ya que usaban cuerdas sencillas en sus guitarras ${ }^{22}$.

Por los tiempos en que Vargas y Guzmán escribía su tratado se gestaba también un cambio en la notación musical para la guitarra. La tablatura usada desde fines del siglo XV para expresar por escrito la música de los instrumentos punteados, tales como el laúd, la vihuela y la guitarra, empezó a verse desplazada por la notación convencional en pentagrama. Este sistema hizo su aparición a mediados del siglo XVIII: en 1758 se vendía en Madrid y Paris un método anónimo para guitarra, firmado por un cierto "Don ***" [sic], en el cual la música aparece tanto en tablatura como en notación convencio-

21 Vargas 1773, p. 11; Vargas 1777, II, pp. 6-7. Ferrandiere, op. cit., pp. 1-2, menciona que únicamente el sexto orden está octavado, y que la prima es normalmente sencilla.

22 Citado por H. Turnbull, op, cit., p. 63. 
nal ${ }^{23}$. A finales de ese mismo año el Journal de Musique de Lagarde también incluyó música para guitarra en notación en pauta, y alrededor de tres años más tarde este mismo sistema de escritura se encuentra en un libro llamado Le Guide des Écoliers de Guitarre [...] EEuvre VIle (Paris: Mad. ${ }^{\text {me }}$ Oger, c. 1761), debido a Giacomo Merchi ${ }^{24}$. Una obra ligeramente posterior, escrita por Michel Corrente, Les dons d'Apollon (Paris, 1763), describe como nuevo el uso de la clave de sol transpositora a la octava baja, misma que sigue en uso actualmente ${ }^{25}$. El tratado de Vargas aparece justo en medio del periodo que podríamos llamar de transición de la tablatura hacia la notación en pauta, y el autor se hace eco del pensamiento reformador, defendiendo las ventajas de la notación convencional sobre la tablatura, si bien condesciende a explicar el uso de esta última, tal y como lo había hecho algunos años antes "Don ***”:

"el que deseare aprender la Guitarra con perfeccion debe huir de que lo enseñen por el modo que llaman cifra porque no es el más primoroso ni seguro, como se dijo en el prólogo, aunque, por si se quiere seguirlo se explica con claridad"26.

Las diferencias entre estas primeras fuentes en notación convencional y la notación usada actualmente para la música de guitarra son relativamente pocas: grafía distinta de algunos símbolos, diferente colocación de las notas largas en el compás, y la carencia de indicaciones sobre la marcha de las diferentes voces. Las sonatas morelianas, al haber pasado por las manos de un copista moderno, no acusan ninguna de las primeras dos características; lo que sí aparece es la indiferencia hacia la separación de las voces en lo que a la escritura se refiere, característica que se ha identificado como típica de las fases más primitivas del uso de la notación convencional para guitarra ${ }^{27}$. De todo esto se puede inferir que el proceso de transición en la grafía musical que tenía lugar en Europa tuvo ecos en la Nueva España, donde pudo encontrar un terreno fértil en los centros mas importantes de población. La falta de fuentes provenientes de la capital impide afirmar con certeza que los guitarristas de la ciudad de México adoptaran también el nuevo sistema en este periodo, pero todo hace pensar que también lo harían así.

Los compases usados en las sonatas de Morelia son 2/4, $3 / 4$ y 3/8, todos ellos descritos en el tratado de Vargas y Guzmán. Del compás de 2/4 nos dice que "tiene dos movimientos, vno al Dar y otro al Alzar"; del compás de 3/4 señala que "tiene tres Movimientos repartidos en vno al dar y dos al Alzar"; finalmente declara que el compás de 3/8 tiene "su ayre como el de los tresillos, aunque muchas vezes se lleva como el de tres por Quatro" 28 . La descripción de la forma de marcar el compás de 3/4

23 La referencia al método de "Don ***", así como la reproducción de una de sus páginas mostrando la música en tablatura y notación convencional, aparece en el artículo de Matanya Ophee, "A Brief History of Guitar Methods", publicado en su página web: http://www.guitarandluteissues.com/methods/methods.htm (acceso: 4/VI/2007).

24 La referencia al Journal de Musique se encuentra en James Tyler, The Early Guitar (Londres: Oxford University Press, 1980), p. 134. Hay una edición en facsímil de la obra de Merchi, publicada por Minkoff Reprint (Ginebra, 1981).

25 Citado en H. Turnbull, op. cit., loc. cit.

26 Vargas 1773, p. 42; Vargas 1776, II, p. 9. Todavía en 1789 se anunciaban en la Gazeta de Barcelona obras en cifra para guitarra, véase la nota 12, y en 1799 se publicó una reedición del método de Abreu para "guitarra de cinco y seis ordenes, véase la nota 13.

27 Véase el artículo de Matanya Ophee, "New Light on the So-called 'Modern' Guitar Notation”, Guitar \& Lute, No. 27 (Marzo 1983), pp. 20-28 (pp. 25-26).

28 Vargas 1776, II, pp. 41-42. En Vargas 1773, p. 52 aparecen las mismas descripciones de los compases de 2/4 y 3/4, pero la del compás de $3 / 8$ es más sencilla, limitándose a señalar que "se compone de tres movimientos, dándose dos en bajo y uno en alto. Entran en un compás tres corcheas; seis semicorcheas, otro, etc. Se figura con un tres y abajo un ocho". 
ofrecida por Vargas tiene puntos en común con aquella que proporciona fray Tomás de Santa María en su Arte de tañer fantasia (1565), así como con otros tratados posteriores. Según Santa María:

"el compas de la proporcion que por otro nombre llaman Ternario [...] de tres partes que tiene, las dos se gastan en el golpe que hiere en baxo, y la otra en el que hiere en alto"29.

Esta cita de Santa María se ha traído a colación como una pequeña prueba de un hecho patente en la historia de la teoría musical española, y que puede tener consecuencias para las sonatas morelianas: la renuencia a abandonar ciertas reglas y conceptos tradicionales, aun cuando ya se hubieran rebasado en la práctica. En el caso de las sonatas, las rúbricas "Sonata 5" y "Sonata 8" plantean un problema: ¿se trata, en efecto, de la quinta y octava sonatas de la serie de catorce que menciona Bernal Jiménez en su artículo de 1952? Si bien éste pudiera ser el sentido de las rúbricas, también es posible sugerir una interpretación diferente: los números en cuestión podrían no referirse a un orden determinado dentro de una serie de piezas, sino a su tonalidad, o mejor dicho, a su modalidad. A pesar de que en la segunda mitad del siglo XVIII los principios de la tonalidad ya estaban firmemente establecidos en el resto de Europa, los teóricos españoles seguían manteniendo el sistema modal vigente desde el renacimiento, adaptándolo ahora a las nuevas necesidades. Por lo tanto, no resulta extraño encontrar en la música española del siglo XVIII títulos como "Sonata del quinto tono", o bien "Sonata del octavo tono". El mismo Vargas y Guzmán dedica un capítulo de su tratado a los "tonos de el Canto de Organo", donde explica, siguiendo la tradición, que el quinto y sexto modos tienen su final (o tónica) en Fa, y el séptimo y octavo en Sol; sin embargo aclara unas líneas más adelante que en la práctica la final del quinto tono era por lo general $D^{30}$. Ahora bien, la "tonalidad" de la sonata "ocho" de Morelia es, precisamente, Sol mayor, tal y como sucede en otras sonatas españolas del octavo tono de la misma época ${ }^{31}$. La sonata "cinco", sin embargo, no parece ceñirse al patrón modal ya que se encuentra en la "tonalidad" de Mi y no en la de Do; no obstante, el mismo Vargas declara que los modos podían transportarse, en cuyo caso se llamaban accidentales, e indicando que los transportes más habituales para el quinto tono eran Si bemol y Re ("segundillo" y "punto alto" respectivamente) ${ }^{32}$. La sonata cinco tampoco se conforma con estas transposiciones, pero Vargas también señala que:

"Hay otros tonos tambien accidentales, y se forman atendiendo siempre a el Diapazon de el Natural, y assi se le ponen los Sobstenidos o 1[os] Bemoles que le combienen aunque nunca es bueno pasar de quatro Accidentes" 33 .

Si se añade a esto que el quinto modo, según Vargas y sus predecesores, tenía tercera mayor, es decir que se trataba de un modo mayor, se podría concluir que la "quinta sonata" pudiera estar en un

\footnotetext{
29 Fray Tomás de Santa María, Libro llamado arte de tañer fantasia (Valladolid: Francisco Fernández de Córdoba, 1565), fol. 8. Véase también a Samuel Rubio, La polifonía clásica (Madrid: Biblioteca "La Ciudad de Dios", 1956), pp. 21-23 para referencias a otros tratadistas que señalan cómo el compás ternario debía marcarse en dos movimientos.

30 Vargas 1773, p. 76; Vargas 1776, II, p. 98.

31 Véase, por ejemplo, Antonio Bacieiro (ed.), Nueva biblioteca española de música de teclado. Siglos XVI al XVIII, 7 vols (Madrid: Unión Musical Española, 1980-1984), vol. 2 (1981), el cual contiene dos sonatas anónimas, otra de Anselmo Viola, y una más de Joaquin Oxinagas, todas ellas del siglo XVIII, del octavo tono, y en la "tonalidad" de Sol mayor.

32 Vargas 1773, p. 77; Vargas 1776, II, pp. 98-99.

33 Ibid; Ibid.
} 
modo transportado, llegando a los límites prescritos para este procedimiento, o sea cuatro sostenidos. Pablo Nassarre ofrece información adicional acerca del transporte de los tonos, y confirma la posibilidad de tañer el quinto tono con final en Mi:

"Los terminos por donde se puede transportar estos dos Tonos [quinto y sexto], son onçe à mas del termino natural, como todos los otros. [...] Por Elami ay tambien dos terminos por donde se puede transportar con medio punto de diferencia. Para el mas alto se han de figurar las claves con quatro sostenidos: y son Fefaut, Gesolreut, Cesolfaut y Delasolre. Por el mas baxo, se hallan algunas composiciones modernas, que aunque son tan proprias de quinto, se tienen como de sexto punto baxo: que como el Diapasón es todo uno es de qualquiere de los dos, à quien se quisiere apropiar. Deven figurarse las claves para semejantes composiciones con tres Bemoles: que son en Elami, Alamire, y Befabemi" 34 .

Si añadimos a esto que el "diapasón", del quinto tono, es decir su estructura interválica, se conforma, todavía siguiendo a Nassarre, con el esquema "Ut, re, mi, fa, sol, re, mi fa", es decir, exactamente la misma disposición de una escala diatónica mayor, no resulta tan arriesgado proponer la identificación de la sonata "en Mi" como una sonata del quinto tono, evidentemente transportado ${ }^{35}$.

Otro punto en el cual las sonatas de Morelia coinciden con lo expuesto por Vargas y Guzmán es en el uso de algunos tipos de arpegios. Según este tratadista, los arpegios podían ser de cinco tipos: de dos, de tres, de cuatro, de ocho movimientos y de campanela (Ilustración 16); la única diferencia entre la campanela y el arpegio de ocho movimientos consiste en la digitación utilizada ${ }^{36}$. Ejemplos del arpegio de dos movimientos se pueden encontrar en la Sonata 8, primer movimiento, compases 26- 28; de tres movimientos en la misma sonata, segundo movimiento, compases 28-30 y 61-66; y de cuatro movimientos en la Sonata 5, primer movimiento, compases 40 y 43.

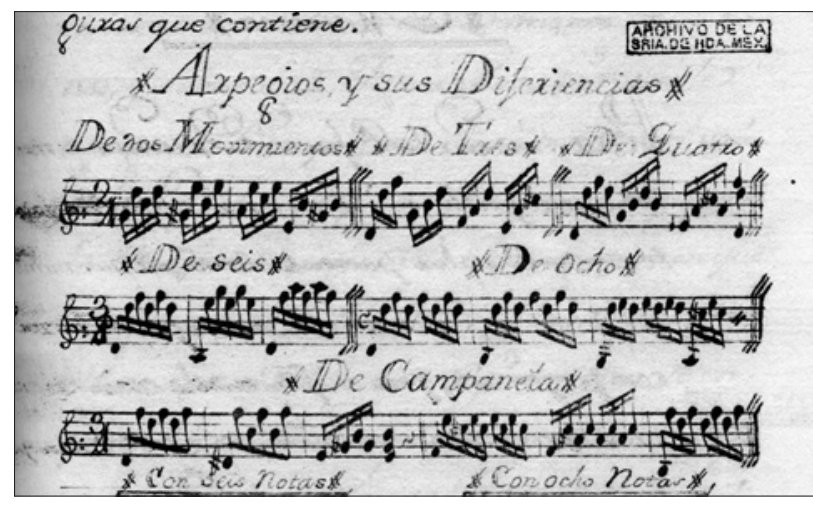

Ilustración 16. Antonio de Vargas y Guzmán: Explicación para tocar la guitarra..., p.67: “Arpegios y sus Diferencias".

34 Pablo Nassarre, Escuela Música según la práctica moderna (vol. 1: Zaragoza, 1723; vol. 2: Zaragoza 1724), edición en facsimil: Institución Fernando el Católico (Zaragoza, 1980), II, p. 357.

35 Pablo Nassarre, op. cit., II, p. 356. Es interesante notar que en el canto llano también se llegó a cantar el quinto tono por elami: "El quinto tono se usa de dos modos, uno teniendo su diapasón de elami a elami, como he dicho del tercero, y se a de entender para Psalmos, cantandolo el Coro a Canto Llano", Escuela Música, I, p. 314.

36 Vargas 1773, p. 61; Vargas 1776, II, pp. 64-65. 
De acuerdo con Vargas, para tocar de punteado sólo se usaban tres dedos de la mano derecha: pulgar, índice y medio ${ }^{37}$. Estos dedos son suficientes para tocar los arpegios que describe, así como la mayoría de los que aparecen en las sonatas de Santa Rosa. Sin embargo, la Sonata 8, primer movimiento, compás 18, presenta una figura que requeriría el anular para tocarse, lo cual hace pensar que durante este periodo las innovaciones en materia de notación encuentran su paralelo en el desarrollo de la técnica instrumental.

Una característica de las sonatas que nos ocupan es la falta de bajos, en marcado contraste con las sonatas de Vargas y Guzmán, concebidas para guitarra y continuo. Esta combinación de "guitarra y baxo", netamente hispánica, se puede encontrar en un buen número de las piezas de la colección de la Biblioteca Municipal de Madrid, así como entre los anuncios publicados en la Gazeta de Barcelona entre 1780 y 1789, la fecha aproximada (o ligeramente posterior) de composición de las sonatas morelianas $^{38}$. Por ejemplo, un anuncio fechado el martes 15 de noviembre de 1784 pone a la venta:

"Alegros, pastorelas, guarachas, el fandanguillo avandolado, paspies, minuetes, contradanzas y los baxos de las seguidillas, compuestas por varios artores [sic] á 1 $1^{\text {a }}$ guitarra y baxo: por D. Miguel Brito. Hay una sonata á $1^{\text {a }}$. guitarra, y un quadernito manuscrito para componer por las posturas mayores y menores: trata tambien de la guitarra, de las cuerdas, y del conocimiento de la Música; además hay 6 contradanzas por Máximo Merlo á 1ª guitarra y baxo"39.

De acuerdo con la información proporcionada por otro anuncio del 5 de abril de 1788, el continuo implícito en estos bajos podía ser ejecutado tanto en otra guitarra como en el clave ("Dos tiranas graciosas á solo, con baxo para guitarra ó clave, intituladas el sudor de la tirana, y el fandango Español"), mientras que otro anuncio en el mismo número de la Gazeta describe este género de composición como "moderno":

"Quaderno de seis tiranas y quatro seguidillas á lo volero, dos de las primeras se venden sueltas: compuestas nuevamente con baxo para guitarra según estilo moderno por D. Gil Leocadio Zarzaparrilla, vecino de Madrid. Se hallarán con otros juguetes del mismo autor, en Madrid en la Librería de Gomez. Su precio 32 rs." 40.

La carencia de bajos en las sonatas morelianas sugiere que fueron compuestas para una combinación similar, requiriendo aún más el acompañamiento del continuo que las de Vargas. Esta hipótesis explicaría también el uso de figuras repetidas que, tocadas en una guitarra sola, carecen de sentido musical por su monotonía, como por ejemplo en la Sonata 5, primer movimiento, compases 25-26 y 48-50 (Ilustración 17); y especialmente en la Sonata 8, primer movimiento, compases 26-28 (Ilustración 18). El uso de otro instrumento proporcionando el fundamento armónico daría a estas sonatas la variedad necesaria en las secciones repetitivas. Por esta razón me he atrevido a preparar una versión que incorpora una reconstrucción tentativa del continuo faltante. En esta versión se indican por

37 Vargas 1773, p. 59; Vargas 1776, II, p. 61.

38 Luis Briso de Montano, op. cit., considera a la combinación de guitarra y bajo como una "modalidad netamente española".

39 Josep María Mangado, op. cit.

40 Ibid. 
medio de pequeños números las correcciones editoriales; las alteraciones sugeridas se indican de manera convencional con pequeños accidentes sobre las notas; asimismo he interpolado entre los compases 53 y 54 del segundo movimiento de la Sonata 8 una pequeña sección (indicada entre corchetes) que soluciona de manera más congruente la marcha armónica deficiente mencionada arriba.

\section{Figuras repetidas}

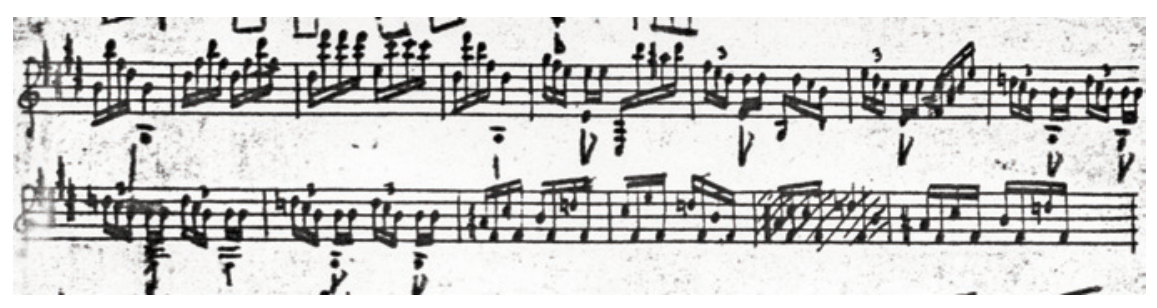

Ilustración 17. Sonata 5, Allegro, compases 41-53.

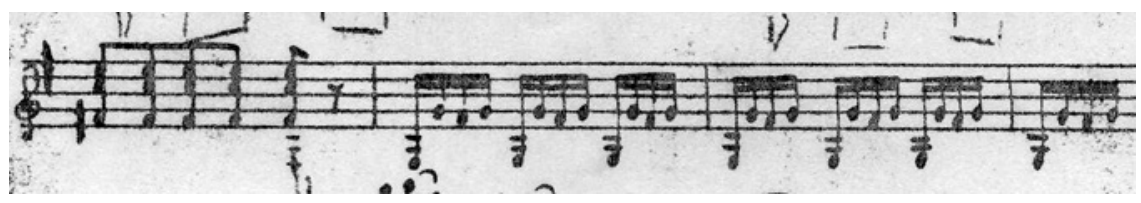

\section{Ilustración 18. Sonata 8, Adagio poco andante, compases 25-28.}

Es evidente que la interpretación de estas sonatas siguiendo criterios históricos requeriría la realización del continuo en alguno de los instrumentos usuales en el ámbito hispánico de la época: clave, arpa o, incluso, otra guitarra siguiendo la evidencia de los anuncios de la Gazeta de Barcelona y, especialmente, la práctica descrita en el tratado de Vargas y Guzmán, quien dedicó más de la mitad de su obra a la "Guitarra de Baxo". Si la hipótesis postulada anteriormente sobre la procedencia de estas obras como parte de la serie de catorce sonatas para dos guitarras del Archivo Musical de Santa Rosa de Valladolid, es correcta, una segunda guitarra para el continuo no solo sería adecuada, sino que sería el instrumento más apropiado para realizarlo, y las sonatas morelianas encajarían exactamente en el marco hispánico de la época en el que se encuadran las sonatas para guitarra y continuo de Antonio Vargas y Guzmán. 

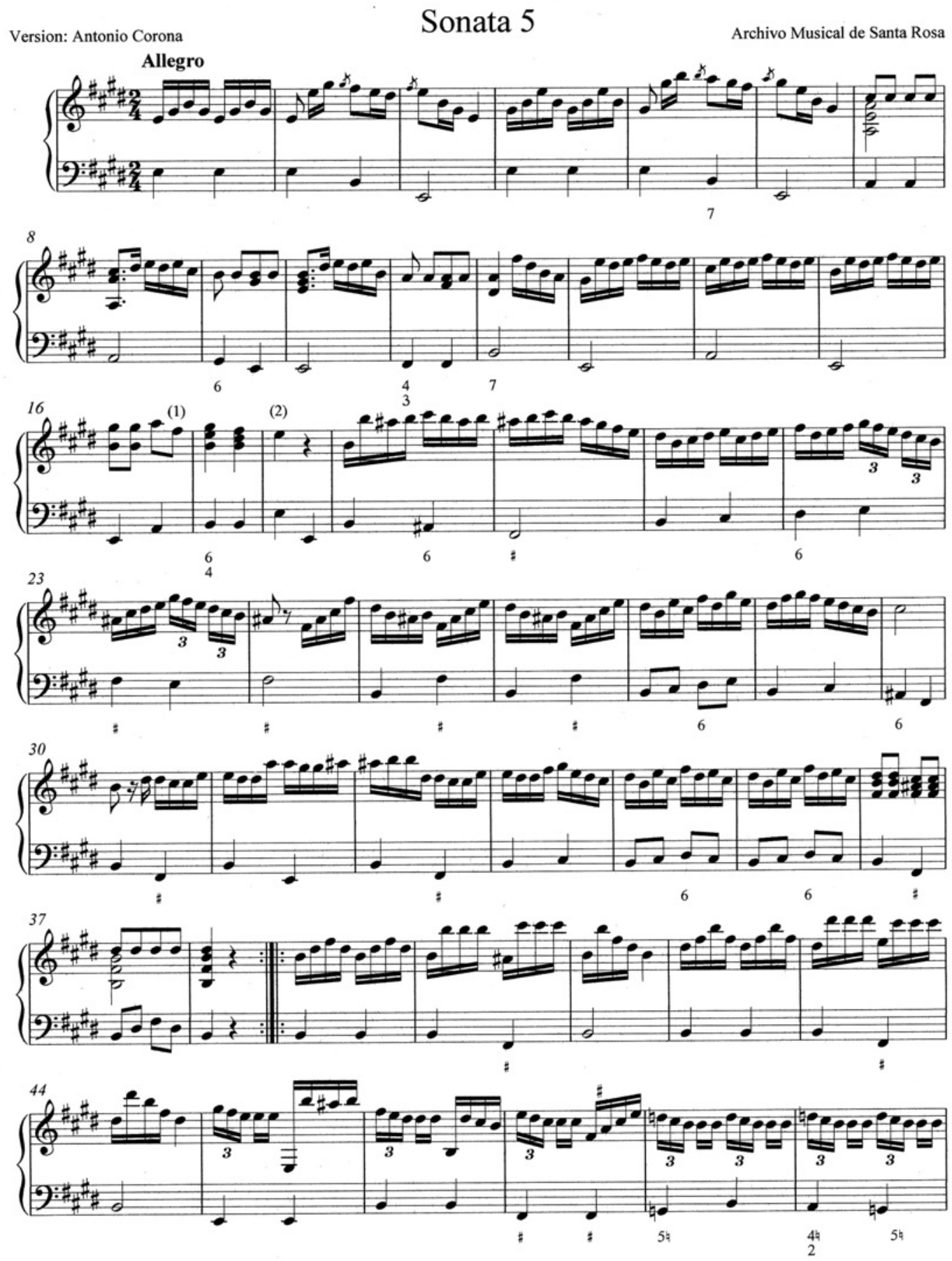
2
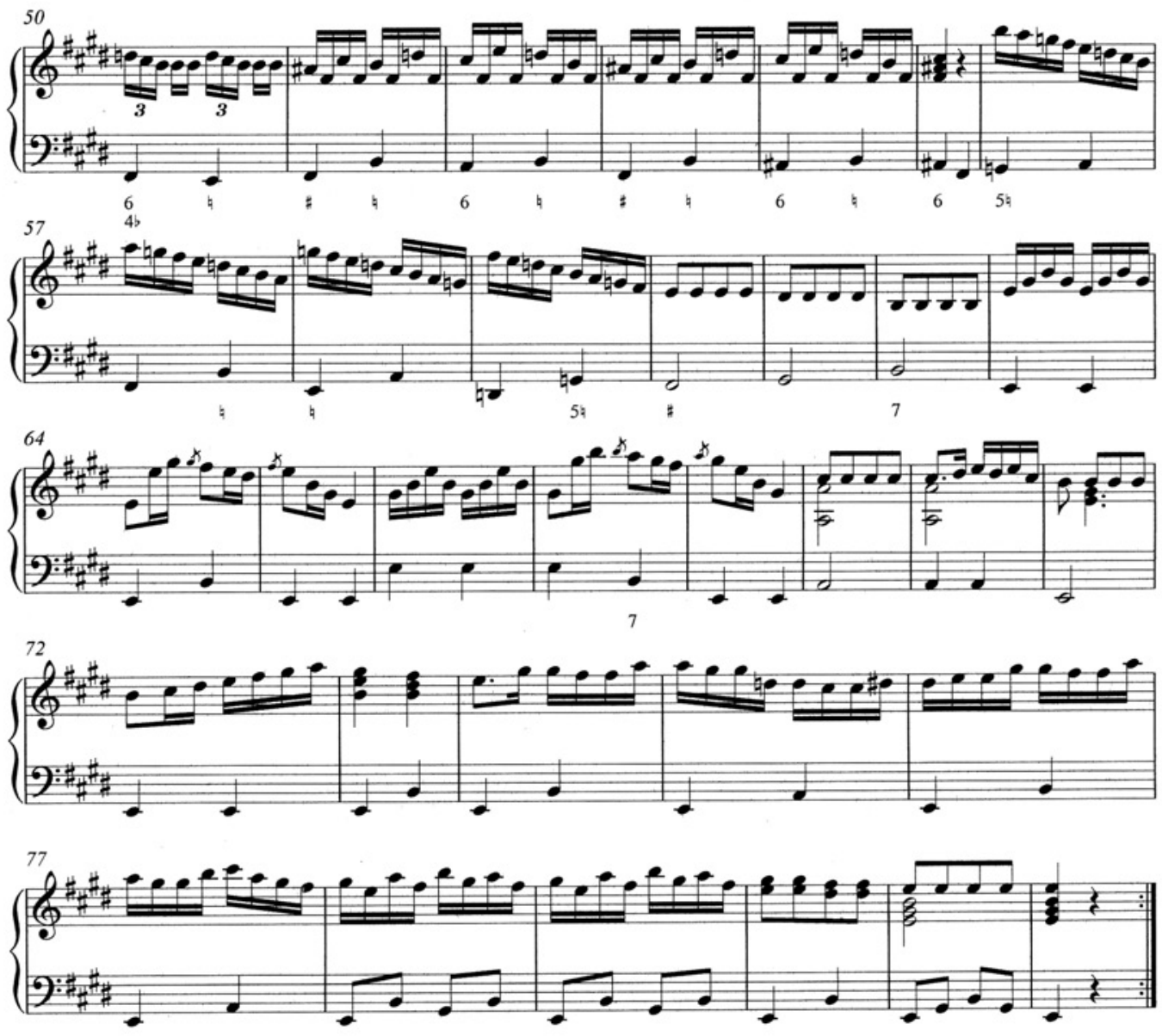

$\begin{array}{lll}\text { (1) Original: Sol } & \text { (2) Original: Fa-La\#-Do Se eliminó un compás duplicado (23) }\end{array}$ 

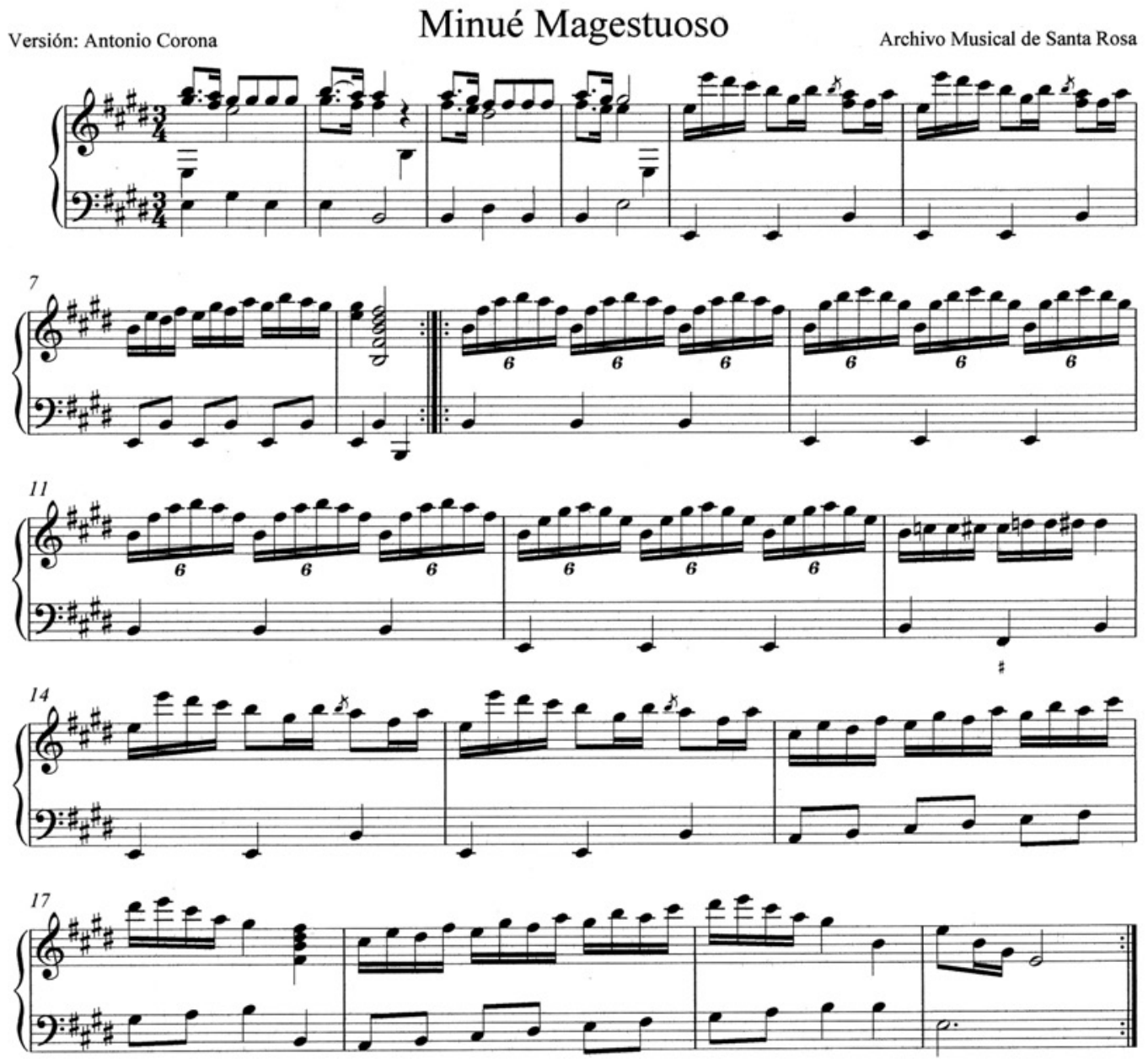
$\begin{array}{lll}\text { Versión: Antonio Corona } & \text { Sonata } 8 & \text { Archivo Musical de Santa Rosa }\end{array}$
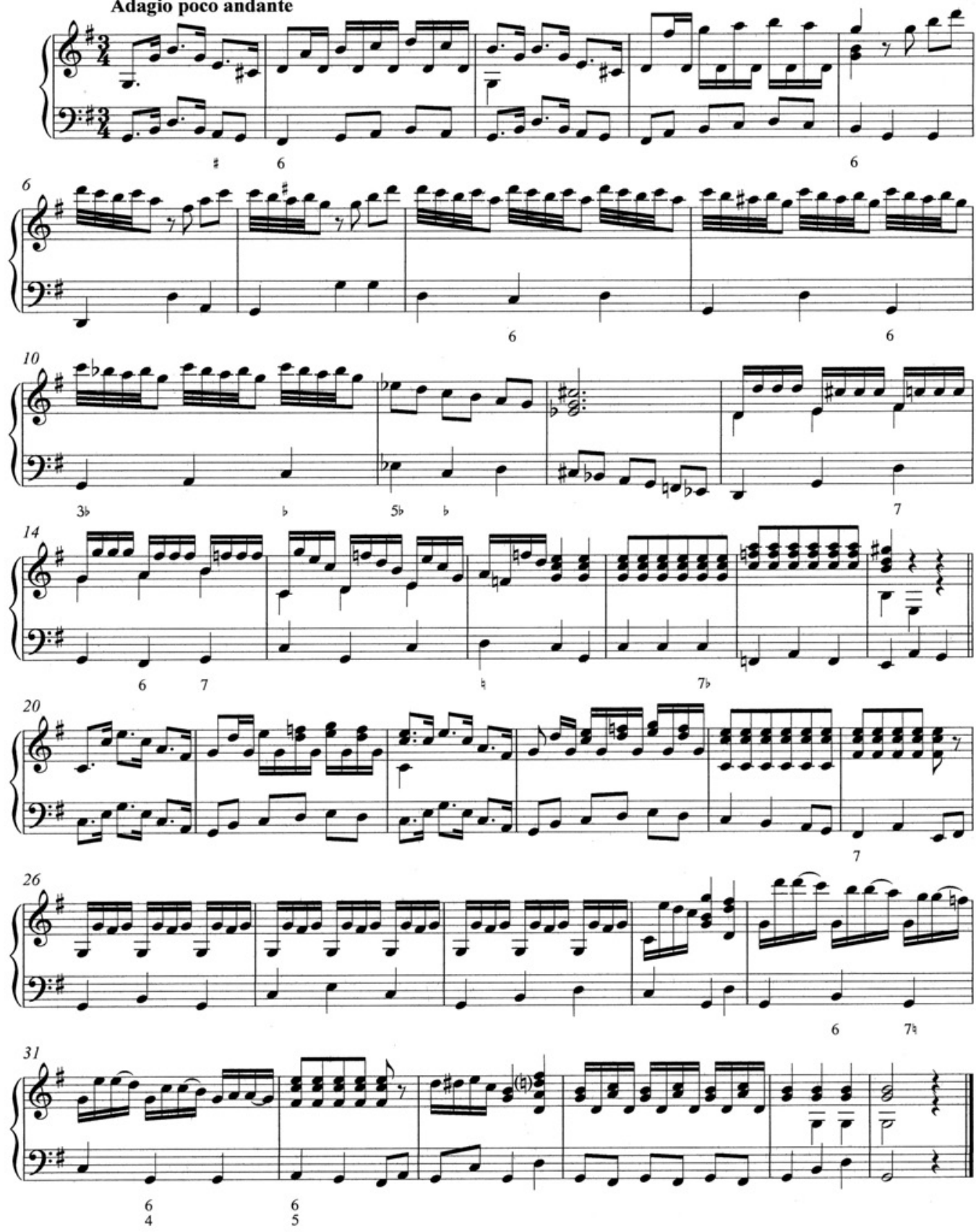

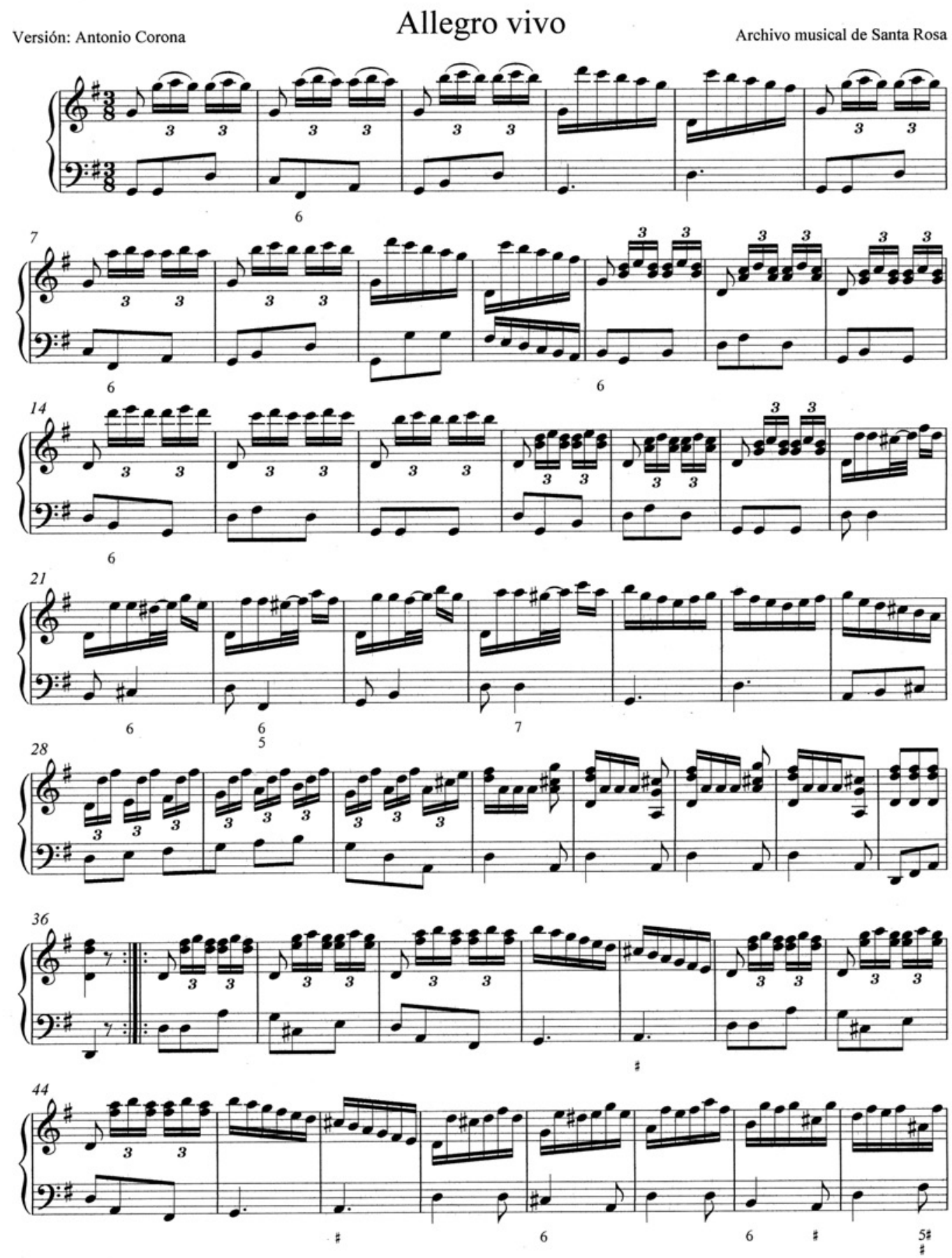

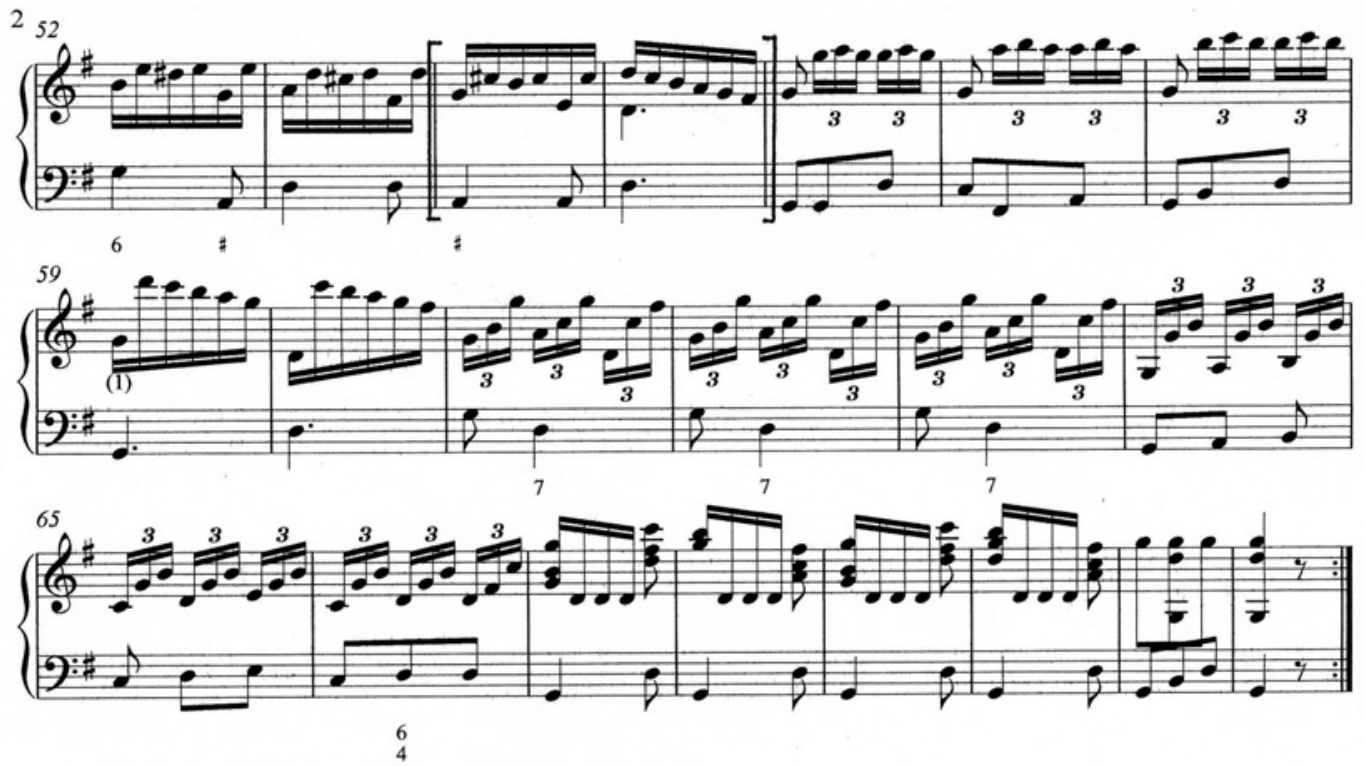

(1) Original: $\operatorname{Re}$ 